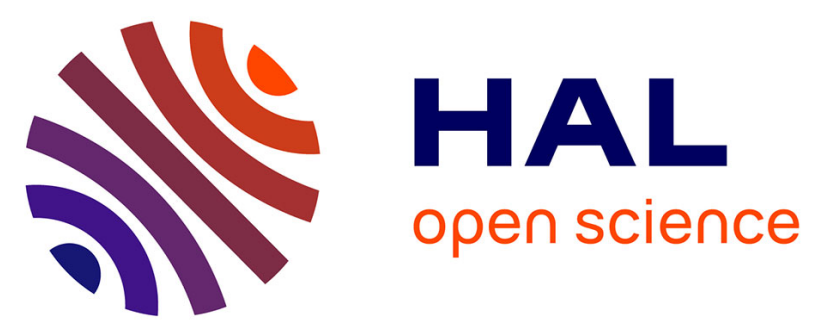

\title{
Experimental Mid-Infrared Supercontinuum Generation in a Germanium on Silicon Waveguide
}

\author{
Alberto Della Torre, Milan Sinobad, Rémi Armand, Barry Luther-Davies, Pan \\ Ma, Stephen Madden, Jean-Michel Hartmann, Vincent Reboud, Jean-Marc \\ Fedeli, Christelle Monat, et al.
}

\section{To cite this version:}

Alberto Della Torre, Milan Sinobad, Rémi Armand, Barry Luther-Davies, Pan Ma, et al.. Experimental Mid-Infrared Supercontinuum Generation in a Germanium on Silicon Waveguide. OSA Advanced Photonics Congress, Jul 2020, Washington, United States. pp.JTu3A.3, 10.1364/IPRSN.2020.JTu3A.3 . hal-03295593

\section{HAL Id: hal-03295593 \\ https://hal.science/hal-03295593}

Submitted on 22 Jul 2021

HAL is a multi-disciplinary open access archive for the deposit and dissemination of scientific research documents, whether they are published or not. The documents may come from teaching and research institutions in France or abroad, or from public or private research centers.
L'archive ouverte pluridisciplinaire HAL, est destinée au dépôt et à la diffusion de documents scientifiques de niveau recherche, publiés ou non, émanant des établissements d'enseignement et de recherche français ou étrangers, des laboratoires publics ou privés. 


\title{
Experimental Mid-Infrared Supercontinuum Generation in a Germanium on Silicon Waveguide
}

\author{
Alberto Della Torre, ${ }^{1,4}$ Milan Sinobad, ${ }^{1}$ Rémi Armand, ${ }^{1}$ Barry Luther-Davies, ${ }^{2}$ Pan $\mathrm{Ma},{ }^{2}$ Stephen Madden, ${ }^{2}$ \\ Jean-Michel Hartmann, ${ }^{3}$ Vincent Reboud, ${ }^{3}$ Jean-Marc Fedeli, ${ }^{3}$ Christelle Monat, ${ }^{1}$ and Christian Grillet ${ }^{1}$ \\ ${ }^{1}$ Université de Lyon, Institut des Nanotechnologies de Lyon (INL), 69131 Ecully, France \\ ${ }^{2}$ Laser Physics Center, Australian National University, Canberra, ACT 0100, Australia \\ ${ }^{3}$ Université Grenoble Alpes, CEA-Leti, 38054 Grenoble Cedex 9, France \\ ${ }^{4}$ e-mail : alberto.della-torre@ec-lyon.fr
}

\begin{abstract}
We report the first experimental supercontinuum generation in a germanium waveguide. By pumping a low-loss germanium on silicon waveguide with $\approx 200 \mathrm{fs}$ pulses at 4.6 $\mu \mathrm{m}$, we generated a supercontinuum extending from 3.53 to $5.83 \mu \mathrm{m}$.

(C) 2020 The Authors
\end{abstract}

\section{Introduction}

In the last two decades, germanium has played a key role in group IV photonics. The first applications of germanium in integrated photonics were addressed to devices operating in the near-infrared [1,2]. More recently, however, the wide transparency window up to $15 \mu \mathrm{m}$ [3] and its theoretically anticipated attractive nonlinear properties [4] have led to high expectations for germanium to become a promising material for (from 3 to $13 \mu \mathrm{m}$ ) photonics. In terms of fabrication, tremendous progress has been made in the last years, with several demonstration of low-loss germanium on silicon waveguides in the mid-infrared region [1]

Photonics in the mid-infrared has a large number of applications based on the optical detection of molecules that can be readily identified through measuring their strong fundamental absorption lines in this band [3]. A broadband source, such as a supercontinuum, is a fundamental element for integrated sensing platforms since it allows for parallel detection of multiple gas species [5]. On-chip mid-infrared supercontinuum generation has been demonstrated in several group IV platforms [5-8]. Supercontinuum generation up to $8.5 \mu \mathrm{m}$ has been demonstrated by our group in silicon-germanium on silicon waveguides, reaching the onset of the absorption from the silicon substrate [7]. In this latter platform, we have also demonstrated the possibility of precisely controlling the supercontinuum coherence properties $[9,10]$. Due to its a priori wider transparency window [11], pure germanium on silicon waveguides are anticipated to overcome the current limits of the other group IV platforms. So far, however, supercontinuum generation in germanium waveguides has been limited to numerical demonstrations.

Here we report the first experimental demonstration of supercontinuum generation in a germanium waveguide. We pumped a $4.46 \mu \mathrm{m} \times 2.57 \mu \mathrm{m}$ cross-section germanium on silicon air-clad waveguide with $\approx 200 \mathrm{fs}$ pulses at 4.6 $\mu \mathrm{m}$, generating a supercontinuum extending from 3.53 to $5.83 \mu \mathrm{m}$. Owing to the transparency of atmosphere between 3 and $5 \mu \mathrm{m}$ and to the strong absorption of hazardous and greenhouse gases such as $\mathrm{CO}(\sim 4.5 \mu \mathrm{m})$, $\mathrm{CO}_{2}$ $(4.2,4,3 \mu \mathrm{m})$ and $\mathrm{CH}_{4}(3.45 \mu \mathrm{m})$ [12], our source has potential applications in free-space communications and environmental monitoring.

\section{Supercontinuum Generation}

A $4.46 \mu \mathrm{m}$ wide, $2.57 \mu \mathrm{m}$ thick air-clad germanium on silicon waveguide (fig. 1a inset) was designed to have low dispersion beyond $4 \mu \mathrm{m}$ (fig. 1a). We measured propagation loss of $\approx 1.25 \mathrm{~dB} / \mathrm{cm}$ between 3.5 and $4.5 \mu \mathrm{m}$. Supercontinuum generation is achieved by pumping the waveguide with $\approx 200 \mathrm{fs}$ TE polarized pulses from a midinfrared MIROPA-fs optical parametric amplifier at a repetition rate of $63 \mathrm{MHz}$. By pumping at $4.6 \mu \mathrm{m}$ in the normal dispersion regime we obtain the spectra shown in Fig $1 \mathrm{~b}$. When pumped with $82 \mathrm{~mW}$ coupled average pump power (corresponding to $3.46 \mathrm{~kW}$ coupled peak power), a $2.3 \mu \mathrm{m}$ bandwidth $(3.53-5.83 \mu \mathrm{m})$ at $-30 \mathrm{~dB}$ level is achieved. Our modeling work shows that this long wavelength boundary is mainly limited by the high free-carrier absorption beyond $6 \mu \mathrm{m}$ [13]. Yet, our supercontinuum covers the 3-5 $\mu \mathrm{m}$ atmospheric transparency window, already making it particularly interesting for free-space communications and environmental monitoring. 
(a)

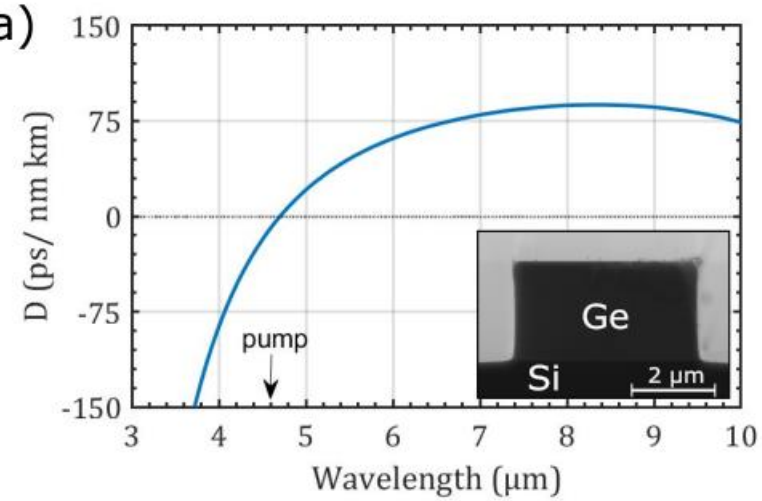

(b)

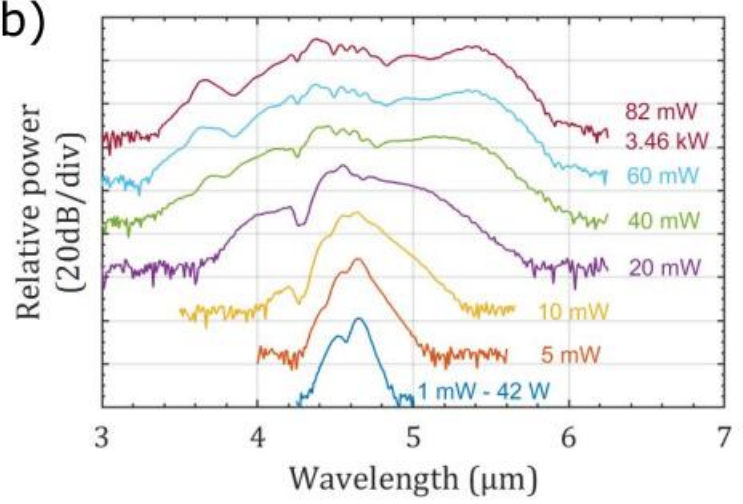

Fig. 1: (a) Dispersion parameter of the $4.46 \mu \mathrm{m} \times 2.57 \mu \mathrm{m}$ cross-section germanium on silicon waveguide. A Scanning Electron Microscope image of the waveguide is shown in the inset. (b) Output spectra measured at different coupled average powers.

\section{Conclusion}

In conclusion, we have demonstrated the first experimental supercontinuum generation in a germanium waveguide. The supercontinuum covers the $3.53-5.83 \mu \mathrm{m}$ band. The multiphoton absorption and therefore the generation of freecarriers could be reduced by pumping at longer wavelengths [14], potentially allowing to fully exploit the transparency up to $12 \mu \mathrm{m}$ [11] of the germanium on silicon platform.

Acknowledgments. We acknowledge the support of the International Associated Laboratory in Photonics between France and Australia (LIA ALPhFA), the Agence Nationale de la Recherche (MIRSICOMB, ANR-17-CE24-0028) and the European Research Council (ERC) under the European Union's Horizon 2020 program (GRAPHICS 648546).

\section{References}

[1] D. Marris-Morin et al., "Germanium-based integrated photonics from near- to mid-infrared applications," Nanophotonics 7, 1781-1793 (2018).

[2] V. Reboud et al., "Germanium based photonic components toward a full silicon/germanium photonic platform," Prog. Cryst. Growth Charact. Mater. 63, 1-24 (2017)

[3] R. Soref, "Mid-infrared photonics in silicon and germanium," Nat. Photonics 4, 495-497 (2010).

[4] N. K. Hon, R. Soref, and B. Jalali, "The third-order nonlinear optical coefficients of $\mathrm{Si}, \mathrm{Ge}$, and $\mathrm{Si}_{1-}{ }_{x} \mathrm{Ge}_{x}$ in the midwave and longwave infrared," J. Appl. Phys. 110, 011301 (2011).

[5] Eirini Tagkoudi et al., "Parallel gas spectroscopy using mid-infrared supercontinuum from a single Parallel gas spectroscopy using midinfrared supercontinuum from a single Si 3 N 4 waveguide," Opt. Lett. 45, 2195-2198 (2020).

[6] N. Singh, et al., "Midinfrared supercontinuum generation from 2 to $6 \mu \mathrm{m}$ in a silicon nanowire," Optica 2, 797 (2015).

[7] M. Sinobad, et al., "Mid-wavelength Infrared Supercontinuum Generation Spanning 1.4 Octaves in a Silicon-Germanium Waveguide," Optica 5, 360 (2018).

[8] N. Nader et al., "Infrared frequency comb generation and spectroscopy with suspended silicon nanophotonic waveguides," Optica 6, 12691276 (2019).

[9] M. Sinobad et al., "Dispersion trimming for mid-infrared supercontinuum generation in a hybrid chalcogenide/silicon-germanium waveguide," J. Opt. Soc. Am. B 36, A98 (2019).

[10] M. Sinobad, et al., "High coherence at $\mathrm{f}$ and $2 \mathrm{f}$ of mid-infrared supercontinuum generation in silicon germanium waveguides," IEEE J. Sel. Top. Quantum Electron. 26, 1-8 (2019).

[11] G. Z. Mashanovich, et al., "Group IV mid-infrared photonics [ Invited ]," Opt. Mater. Express 8, 1040-1043 (2018).

[12] V. M. Lavchiev and B. Jakoby, "Photonics in the Mid-Infrared: Challenges in Single-Chip Integration and Absorption Sensing," IEEE J. Sel. Top. Quantum Electron. 23, (2017).

[13] M. Nedeljkovic, R. Soref, and G. Z. Mashanovich, "Predictions of free-carrier electroabsorption and electrorefraction in germanium," IEEE Photonics J. 7, (2015).

[14] D. Seo, et al., "Multiphoton absorption in germanium using pulsed infrared free-electron laser radiation," Phys. Rev. B - Condens. Matter Mater. Phys. 83, 1-6 (2011). 